\title{
A Probe into the Socio-economic Benefits of Bicycle Sharing
}

\author{
Xiaohai Xia ${ }^{1, a}$, Jianhong $\mathrm{Wu}^{2, b}$ \\ 1,2School of Economics and Management, Beijing Jiaotong University, Beijing, China \\ a16120533@bjtu.edu.cn, bwujh@bjtu.edu.cn
}

Keywords: Bicycle sharing, Socio-economic benefits, Sustainable transportation.

\begin{abstract}
With the rapid development of the Internet and the rapid spread of mobile Internet, an emerging concept, sharing economy, is increasingly being used in people's daily lives. In this context, bicycle sharing comes into being, and becomes one of the new highlights of the development of sharing economy. What are the socio-economic benefits of the rise of bicycle sharing becomes an issue of concern. This paper first introduces the development background and development status of the bicycle sharing. Second, this paper analyzes the socio-economic benefits of bicycle sharing. It points out that bicycle sharing has unique advantages in promoting sustainable development of transportation. Finally, this paper summarizes the current role of bicycle sharing in sustainable transport development, and looks forward to the future development of bicycle sharing. The results show that door-to-door bicycle-sharing using will reduce the use of private cars to a certain extent, which will bring considerable social benefits and promote sustainable transportation development.
\end{abstract}

\section{Introduction}

Since 2016, the bicycle sharing has started to rise in China and has quickly become the hot topic of discussion. Under the background that environment problems are becoming more and more prominent and traffic jams are emerging constantly, how bicycle sharing can play a role in promoting the development of sustainable transport is worth thinking and researching. Bicycle sharing is a new concept that previously related researches mostly explored the impact of public bicycles, which are like bike sharing, on the social and economic sustainable development. While bicycle sharing can be regarded as one of the new models of public bicycles, there are still great differences compared with the traditional public bicycles, such as convenience and business modes. Therefore, this paper explores the role of bicycle sharing in promoting sustainable transport, aiming at revealing the correlation.

\section{The development of bicycle sharing}

\subsection{Bicycle-sharing development background}

Bicycle sharing is generated in the context of the rapid development of sharing economy. The sharing economy is an economic model for sharing goods, services, data or skills among different subjects through the Internet platform [1]. Its core is based on information technology as the foundation and link to realize the separation of the ownership and the right to use of the product. Rapid development of the mobile Internet in recent years is the technical support for accelerating the sharing mode. In addition, several new technologies emerge, such as Location Based Service (LBS) technology, cloud computing with virtualization technology and distributed computing, which expand the scope of resource sharing. Under the support of such a technical background, the bicycle sharing comes into being. As a form of realization of "Internet +", bicycle sharing takes advantage of the development of mobile Internet technology and the popularity of third-party payment methods and builds a new platform based on LBS and big data to provide a new choice for transportation. 


\subsection{Current development of bicycle sharing}

The concept of bicycle sharing appeared in 2015, with some entrepreneurs and capital beginning to enter the market at that time. It can be described as the first year of the development of bicycle sharing in 2016. One of the most popular bike-sharing companies, Mobike, completed the necessary technical preparations and financial support at that time. In April, the first batch of Mobike bicycles was launched in Shanghai to formally enter the market and then entered Beijing in September to begin its rapid expansion. The other giant, Ofo sharing bicycle, was initially started in Beijing campus. Since the Mobike arrived in Beijing, Ofo began to expand its business scope to enter the urban market. Subsequently, both companies began to rapidly grab market share. On the one hand, in the first-tier cities, the two companies continued to increase the volume of their bikes; on the other hand, the two enterprises continued to enter new cities and expand market spaces. As of March 2017, Mobike has covered 23 cities and the Ofo has covered 33 cities in China. In addition, the two companies also actively explored overseas markets, landing in Singapore one after another and piloting them in the United States.

While Ofo and Mobike are rapidly expanding, some other entrepreneurs have also found potential opportunities to share the market and have chosen to enter it. According to incomplete statistics, as of January 2017, there were 17 companies engaged in bicycle sharing business. However, judging from the number of cities and bicycles put into operation, the two companies, Mobike and Ofo, share the leading position. Overall, the bicycle-sharing industry is still in a stable stage of development, and the market is highly competitive.

\section{The development of bicycle sharing has brought significant social benefits}

The socio-economic benefits brought by the development of bicycle sharing can be mainly divided into two aspects: direct socio-economic benefits and indirect socio-economic benefits. Direct socio-economic benefits mainly refer to the rise of shared bicycles to make the characteristics of traffic travel change, resulting in consumer economic savings. Indirect socio-economic benefits mainly refer to the economic benefits of other factors other than cyclists generated.

\subsection{Direct socio-economic benefits}

This is mainly reflected in the economic benefits of saving travel time by solving the "Last Mile" problem. In the process of using a shared bicycle, working hours (working on an 8-hour basis) have few trips, so the leisure time value can be approximated as the time-saving value when calculating. Assuming the value of leisure time is half the value of working time, the calculation model is as follows:

$$
\mathrm{A}_{1}=0.5 \mathrm{I} * \mathrm{t}^{*} \mathrm{~W}
$$

In the formula (1): "A ${ }_{1}$ ": save time benefits. "I": The average daily number of people who use shared bicycles to access other regular traffic. " $t$ ": Average time saved per person per day. "W": the value of working hours per capita unit.

Taking Shenzhen as an example, the per capita GDP of Shenzhen in 2016 is 167,400 yuan. Assuming that GDP is entirely generated by working hours and $210 * 8$ hours per year, the average per capita GDP per hour is 99 yuan. Each day, 0.4 million people in Shenzhen use shared bicycles to connect with other modes of public transportation. Each person saves an average of half an hour travel time. Each day, it can bring direct socio-economic benefits of 9.9 million yuan. The annual direct benefits are 3.61 billion yuan.

\subsection{Indirect socio-economic benefits}

Indirect economic benefits are mainly due to the emergence of shared bicycles gave birth to the "shared bike + public transport", especially the "shared bike + subway" door-to-door green travel mode, thus reducing the number of cars usage amount. These mainly include carbon dioxide, PM2.5, 
NOx, sulfide emissions and air quality improvement benefits brought by the reduction of car usage. As well as benefits of saving the fossil fuels, benefits of correspondingly alleviating the traffic congestion and reducing the traffic safety accidents together with the land resource saving benefits. Taking the benefits of saving fossil energy as an example, the calculation model is as follows:

$$
\mathrm{A}_{2}=\mathrm{a}^{*} \mathrm{~K} * \mathrm{~S} * \mathrm{C} \text {. }
$$

In the formula (2): " $\mathrm{A}_{2}$ ": The number of gasoline users can save by bicycle sharing each day. "a": The share of shared bicycle users transferred from a private car. " K": The average number of orders of bicycle sharing. "S": Average mileage per order. "C": car fuel consumption per kilometer.

Also taking Shenzhen as an example, according to "Shenzhen Internet Bicycle Development Evaluation and Analysis Report", $\mathrm{a}=9.8 \%, \mathrm{~K}=2,590,000$. Assuming an average mileage of $1.5 \mathrm{~km}$ per order, with a fuel consumption of 8 liters per 100 kilometers of private cars, it can be seen from the calculation that if the same mileage is covered by the private car, 30,458 liters of gasoline will be consumed daily. If taking oil price of 6.59 yuan into consideration, the daily economic benefits of saving fossil fuels amounted to 200 thousand yuan, annually 73.25 million yuan. From the perspective of reducing carbon emissions, according to information provided by BP China's carbon emission calculator, saving one liter of gasoline means reducing $2.3 \mathrm{~kg}$ of carbon dioxide. From calculation above, it can reduce the daily carbon dioxide emissions by 70.1 tons and reduce the annual emission of 25,587 tons of carbon dioxide. In alleviating traffic congestion, according to statistics, the per capita traffic area for bicycles is 6.5 square meters per person, while that for cars is 20 square meters per person, about three times as many as that of bicycles. Therefore, using shared bicycles instead of private cars can effectively reduce the space occupied by roads and ease road congestion. In conclusion, bicycle sharing has a wide range of socio-economic benefits and can effectively promote the development of sustainable transport.

\section{Bicycle sharing has unique advantages in promoting sustainable transportation}

\subsection{Greater convenience helps to change the way people travel.}

Compared to the traditional urban public bicycles, sharing bicycles have great advantages in convenience. Conventional urban public bicycles generally require access from fixed parking docks which have relatively limited coverage, and there may be not available during peak service periods. Thus, conventional public bicycles may have some inconvenience when connecting to other modes of public transportation. Shared bicycles have the characteristics of non-dock access. And since it does not need to be parked in a designated area, users can use shared bicycles to interface with other public transport to achieve door-to-door travel, which is one of the most significant advantages of bicycle sharing. The convenience of bicycle sharing makes it effectively cover areas difficult to directly reach by other means of transportation, such as subways and buses, and plays an important role in solving the "Last Mile" problem of public transportation.

\subsection{The big data of bicycle sharing helps to rationalize traffic planning}

Through LBS technology, bicycle sharing companies can effectively obtain the bikes' driving trajectory. Big data formed by summary statistics on travel data of large numbers of users at different times can effectively show people's traveling regularity, which helps the administration departments plan the transportation network more pertinent and feasible, to optimize the efficiency of transportation and promote the development of sustainable transportation.

\section{Summary and Prospect}

Bicycle sharing has developed in the context of sharing economy. Its development reflects the economic sustainability, environmental sustainability and social sustainability and it meets the 
requirements of sustainable transport. Moreover, bicycle sharing has its own unique advantages in promoting sustainable transport.

As the progress of the development of bicycle sharing gradually accelerates, it also reveals some drawbacks. Unreasonable bicycles delivery resulting in short-term congestion. In the densely populated areas and metro stations, bikes are often parked in disorder. In addition, due to the marked decline in the use of bicycles in the past, the planning and construction of new roads often neglect the need for bicycle traffic. The development of bicycle sharing has led to a sudden increase in the number of bicycles on the road, and the existing planning and road facilities can't meet the demand. What's more, sharing bicycles have significant characteristics of public goods, which results in the user having no incentive to properly protect the bike while using, and even some people keep the sharing bicycles as their own. The moral hazard problem is significant.

Aiming at some problems in bicycle sharing, for example, from the perspective of solving the problem of occupying road space, the government can clarify the parking areas and parking requirements of shared bicycles, so that make the bike parking order more reasonable. On the road planning, according to big data results of bicycle-sharing enterprises, government can rationally plan and improve the construction of bicycle lanes. For the characteristics of public goods, the government can establish a unified credit system for bicycle sharing to encourage the rational use of shared bicycles and avoid moral hazard to a certain extent.

In the context of the crazy influx of capital, the market competition for bicycle sharing continues. The future development trend remains uncertain. The market has not formed a clear profit model yet. In the short term, the competition among enterprises will still be fierce. In the competition, some smaller enterprises may be annexed in the market reshuffle. In the long run, the market environment will tend to be rational. In the future, the PPP model may become the ultimate destination for bicycle sharing.

\section{References}

[1] T. B. Tang and X. J. Wu, Shared economy: A subversive economic model under the background of "Internet +", Scientific Development (Chinese Journal), vol. 12, pp. 78-84, 2015.

[2] Stigson B, Mobility 2030: Meeting the challenges to sustainability, World Business Council for Sustainable Development, 2004.

[3] World Bank, Sustainable transport: Priorities for policy reform, The World Bank, 1996.

[4] W. Y. Niu, The theoretical connotation of sustainable development: The 20th Anniversary of UN Conference on Environment and Development in Rio de Janeiro Brazil, Chinese Population, Resource \& Environment (Chinese Journal), vol. 05, pp. 9-14, 2012.

[5] Commission of the European Communities, Sustainable development indicators to monitor the implementation of the EU sustainable development strategy, Brussels: Commission of the European Communities, 2005. 